\title{
АНАЛИЗ ОСОБЕННОСТЕЙ РЫНКА ТРУДА СКФО И В СРЕДНЕМ ПО РОССИИ
}

\section{(c) 2021 Магомадов Эмин Мухадинович}

кандидат экономических наук, доцент кафедры учета, анализа и аудита в цифровой экономике Чеченский государственный университет, Россия, Грозный

\section{(c) 2021 Башаев Асхаб Алманович}

3 курс Института экономики и финансов

Чеченский государственный университет, Россия, Грозный

(c) 2021 Ильясов Тамерлан Русланович

3 курс Института экономики и финансов Чеченский государственный университет, Россия, Грозный

В данной статье рассматривается рынок труда Северо-Кавказского федерального округа. Актуальность данной темы обусловлена тем, что с каждым годом в регионах СКФО наблюдается рост безработицы на рынке труда, занятого населения становится меньше. В статье рассмотрены теоретические основы рынка труда, выявлены ключевые проблемы безработицы, а также проведён сравнительный анализ по безработице в СКФО и в среднем по России. Для разработки стратегии по борьбе с безработицей, рассматриваются данные консолидированного бюджета по СевероКавказскому Федеральному округу.

Ключевые слова: Рынок труда, уровень безработицы, уровень занятости.

Карл Маркс в своей книге «Капитал» дал интересное определение труду: «Потребление рабочей силы - это и есть труд». Великий экономист выделил несколько глав труду. Карл Маркс утверждает, что труд - это неотъемлемая часть жизни человека, а также труд - это процесс, который совершается между человеком и природой. Согласно главе 5, труд - это процесс, с помощью которого регулируется и контролируется обмен веществ между человеком и природой [1]. На рынке труда существуют специфичные названия, такие как работодатель и работник. Работодатель формирует спрос на труд. Например, вы предприниматель, у которого недавно уволился сотрудник, и вам, разумеется, необходим новый сотрудник. Вы выкладываете объявление в государственный центр занятости населения. Тем самым вы автоматически создаете спрос на вакансию. Спрос формируют компании, работодатели, предприниматели и т.д. Работник же, формирует предложение труда. Например, вам необходимо найти работу, так как у вас нет денежных средств для оплаты коммунальных услуги, вы идете в центр занятости населения и ищете работу. Существуют факторы, которые влияют на спрос на рынке труда [2] (см. рис. 1).

Разберем подробней данные факторы. Под технологиями понимается, мобилизовано ли рабочие место. Необходимо определить, в каком количестве работников вы нуждаетесь. В данном

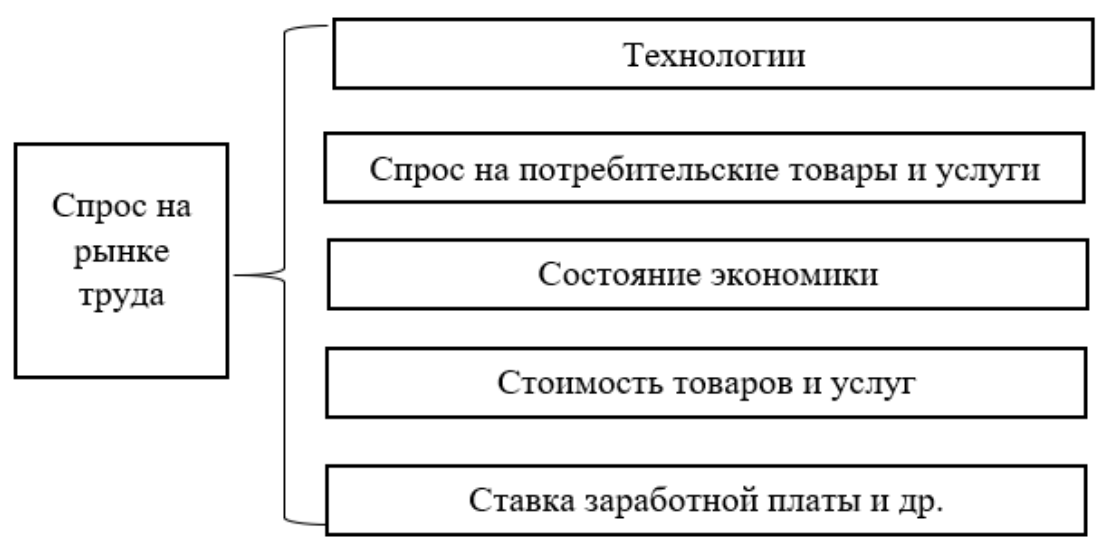

Рисунок 1. Факторы спроса на рынке труда 
случае, если предприятие автоматизировано, то в большом количестве работников необходимость отпадает. Так как будет нецелесообразно нанимать большое количество работников, и формировать на такое предприятие большой спрос на рынке труда тоже нет необходимости.

Говоря о состоянии экономики, отметим, что 2020 год, как всем известно, был очень сложным. Больше всего пострадали такие области как рестораны, кафе, спортзалы и др. Из-за этого, спрос на труд специальностей, связанных с данными отраслями, существенно упал. Также это коснулось и спроса на потребительские товары и услуги.

Качество труда и производительность. Во все времена этот фактор будет неотъемлемым. Качественный труд очень ценится на рынке труда, так как, каждый работодатель, заинтересован в качественно выполненной работе. Приведем пример, предположим, что у вас на предприятии количество работников составляет 10 человек, и они работают качественно и быстро. И у вас есть конкурент, у которого 100 человек, и при этом они работаю некачественно. Разумеется, работодатель будет заинтересован в первом варианте. Стоимость товаров и услуг. Как известно, один и тот же продукт может стоить по-разному. Разумеется, есть товары с разным составом, производители и наценки на товар тоже разные. Всему этому есть логическое объяснение. У малого бизнеса, у которой продукт стоит недорого, и выручка с него небольшая, работа как правило всегда некачественная (под работой подразумевается исключительно работа персонала). У продукта подороже и работа кадров качественней, так как заработная плата намного больше. У предприятий с маленьким денежным оборотом не будет средств для найма новых сотрудников, соответственно, спрос на рынке создавать неце- лесообразно. Помимо спроса существует и предложение. Факторы, которые влияют на предложение на рынке труда изображены на рисунке 2.

Заработная плата является неотъемлемой частью рынка труда, так как без нее люди просто не будут работать. Разумеется, чем выше заработная плата у человека, тем меньше желания уволиться с работы. Или же при поиске работы, почти все, без исключения, ищут для себя престижную и высокооплачиваемую работу. Так было во все времена. Из этого вытекает следующий фактор, уровень способностей и квалификации. Как всем известно, чем выше навык у работника, тем ценнее он становится.

Для повышения навыка работники проходят различные курсы по повышению квалификаций. Естественно ожидать после этого повышения заработной платы или повышения в должности.

Условия труда тоже очень важны, так как не все работники сочтут уместным работать в необорудованном, грязном офисе, где необходимо работать на своем компьютере. Чем выше условия труда, и заработная плата, тем больше желающих будет работать на предприятии. В данной работе проведен сравнительный анализ рынка труда в Северо-Кавказском федеральном округе. А также, акцентировано внимание на показателях по России. Как было сказано выше, 2020 год стал для большинства граждан РФ очень сложным. Уровень безработицы значительно вырос, спрос на труд стал значительно меньше. Проанализируем, рынок труда по Северо-Кавказскому федеральному округу за 2018-2020 год (см. рис. 3).

Как видим, с каждым годом безработица растет, численность занятых людей нестабильна. Например, в Карачаево-Черкесской республике каждый год численность занятых людей стабильно падает, безработица растет. В стати-

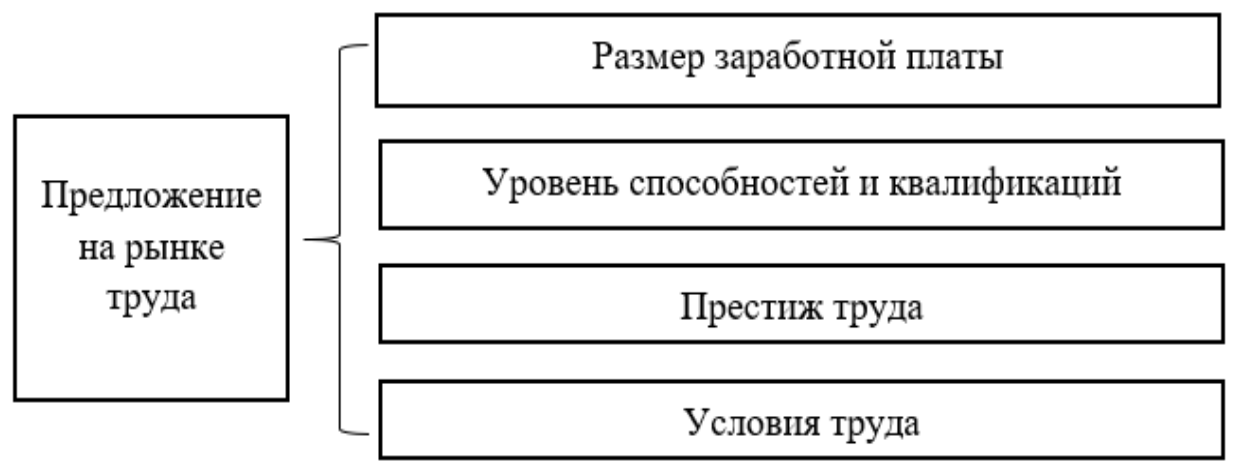

Рисунок 2. Предложение на рынке труда 


\begin{tabular}{|l|l|l|l|l|l|l|l|l|l|l|}
\hline Наименование & \multicolumn{3}{|c|}{$\begin{array}{c}\text { Среднегодовая } \\
\text { численность занятых }\end{array}$} & \multicolumn{3}{c|}{ Занятость } & \multicolumn{3}{c|}{ Безработица } \\
\hline & 2018 & 2019 & 2020 & 2018 & 2019 & 2020 & 2018 & 2019 & 2020 \\
\hline Респ. Дагестан & 1385,3 & 1382,1 & 1351 & 1225,3 & 1202,8 & 1131,1 & 160,0 & 179,3 & 219,9 \\
\hline $\begin{array}{l}\text { Респ. } \\
\text { Ингушетия }\end{array}$ & 248,9 & 251,0 & 236,3 & 182,6 & 184,2 & 180,0 & 66,3 & 66,6 & 83,3 \\
\hline $\begin{array}{l}\text { Кабардино- } \\
\text { Балкар. Респ. }\end{array}$ & 448,2 & 443,1 & 456,7 & 401,2 & 395,4 & 382,2 & 47,0 & 47,7 & 74,4 \\
\hline $\begin{array}{l}\text { Карачаево- } \\
\text { Черкес. Респ. }\end{array}$ & 215,2 & 203,6 & 201,6 & 189,3 & 179,8 & 170,8 & 25,9 & 23,7 & 30,8 \\
\hline $\begin{array}{l}\text { Респ. Северная } \\
\text { Осетия }\end{array}$ & 348,6 & 312,0 & 327,6 & 312,1 & 275,0 & 278,7 & 36,5 & 36,0 & 48,9 \\
\hline Чеченская Респ. & 629,4 & 634,4 & 655,5 & 543,1 & 548,5 & 520,8 & 86,3 & 85,9 & 134,7 \\
\hline $\begin{array}{l}\text { Ставропольский } \\
\text { край }\end{array}$ & 1377,2 & 1382,7 & 1377,0 & 1308,0 & 1315,7 & 1281,6 & 69,0 & 66,9 & 95,4 \\
\hline
\end{tabular}

\section{Рисунок 3. Среднегодовая численность занятых и безработных по СКФО за 2018-2020 год}

стике особое внимание уделяют женщинам и мужчинам. При составлении годового отчета помимо среднегодовой численности занятых и безработных так же создают отдельные пункты с численностью занятых и безработных мужчин и женщин, а также с безработными мужчинами и женщинами.

Как представлено на рисунке 3, численность занятых падает во всех регионах. Для того, чтобы узнать в процентном соотношении уровень безработицы необходима формула (см. рис. 4).

Рассчитаем уровень безработицы (УБ) в республиках. В целом по СКФО численность рабочей силы составляет 4632,7 тыс. человек, из них занятые - 3945,2 тыс. человек, безработные 687,4 тыс. человек.

В Республике Дагестан УБ за 2018 год составляет $11,6 \%$, за 2019 год - 13\%. Безработица в процентном соотношении на 2020 год составляет $16,2 \%$.

В Ингушетии, УБ за 2018год составляет 26,6\%, за 2019 год - 28,8\%. УБ за 2020 год составляет $35,2 \%$.

Уровень безработицы в Кабардино-Балкарии за 2018год составляет $10,5 \%$, за 2019 год - 10,8\%. УБ за 2020 год составляет $16,2 \%$.

В Карачаево-Черкесской республике УБ на 2018 год составляет $12 \%$, за 2019 год - 11,7\%. Можно заметить, что за 2018-2019 год, процент безработицы уменьшился, но в 2020 году он вновь увеличился и составил $15,2 \%$.
В Северной Осетии так же заметно ухудшение ситуации. В 2018 году УБ составляет 10,5\%, в 2019 году - 11,6\%. По состоянию на 2020 год УБ составляет $14,9 \%$.

В Чеченской Республике ситуация выглядит не лучшим образом. В 2018 году УБ составляет $13,7 \%$, в 2019 году $-13,5 \%$, но в 2020 году ситуация ухудшилась и УБ составляет 20,5\%.

В Ставропольском крае ситуация намного лучше, чем у других регионов. В 2018 году УБ составлял 5\%, в 2019 году составлял 4,8\%. Наблюдалось понижение. В 2020 году УБ составляет 6,9\%.

Для лучшей наглядности изобразим полученные на графике (см. график 1).

Исходя из данных графика, можно сделать вывод, что наибольший уровень безработицы за последние года наблюдается в Ингушетии.

Проведем анализ работающего населения в СКФО. К сожалению, занятого населения с каждым годом становится все меньше. В регионах СКФО заметно снижение работающего населения.

Приведем ниже данные по уровню занятости в регионах СКФО (рис. 6), рассчитанные по формуле [2]:

$$
\text { КзН }=\left(\frac{S_{3 \mathrm{H}}}{S}\right) * 100 \%,
$$

где Sзн - численность занятого населения; $\mathrm{S}$ - общая численность населения.

$$
\begin{gathered}
\text { Уровень безработицы }(\%)=\frac{\text { Численность безработных }}{\text { Численность экономически }} \cdot 100 ; \\
\text { активного населения } \\
\text { Рисунок 4. Формула расчета по безработице }
\end{gathered}
$$




\section{Уровень безработицы за 2018-2020 год}

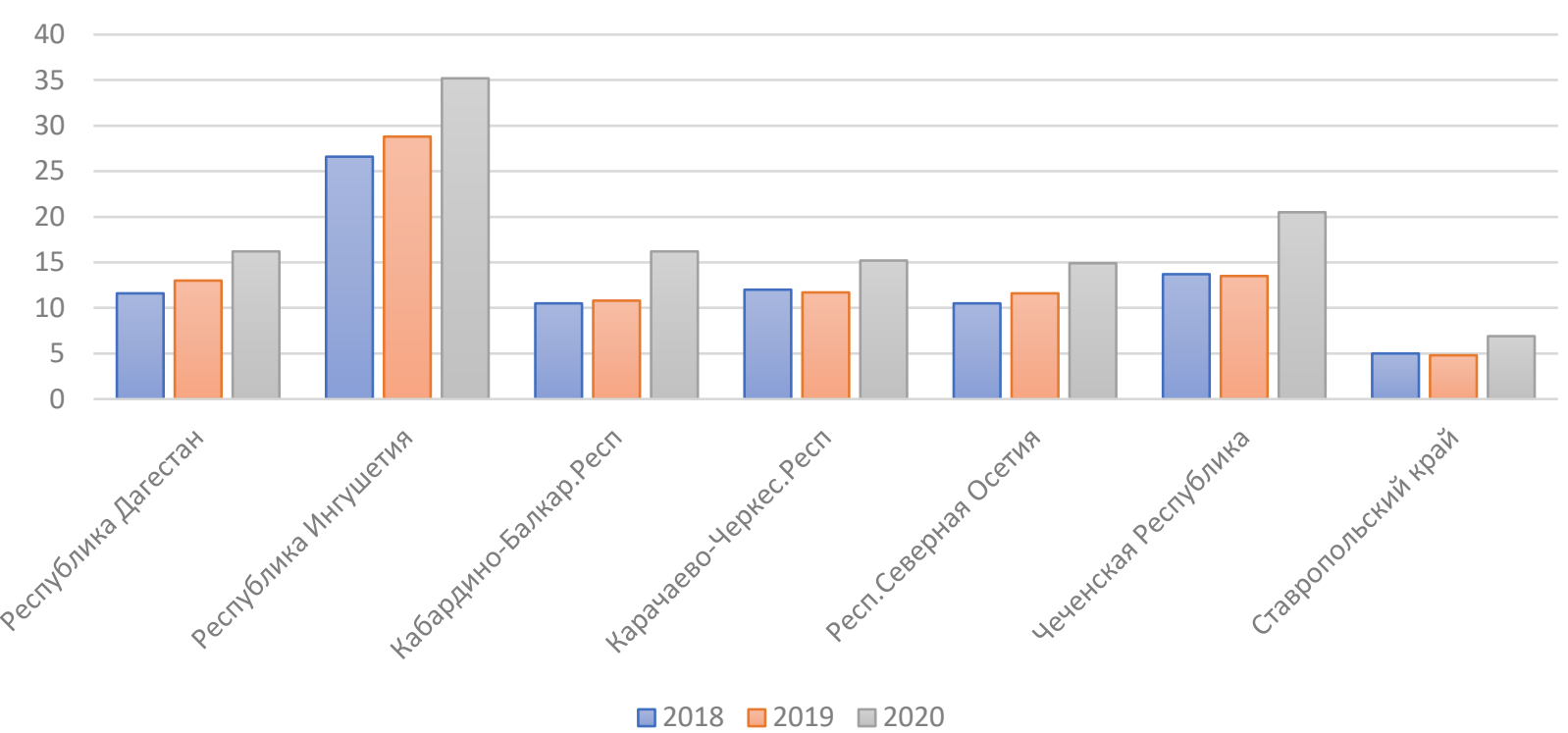

График 1. Уровень безработицы регионов СКФО за 2018-2020 гг.

Исходя из данных рисунка 6, можно сделать вывод, что и занятость населения в регионах также снижается. Елена Варшавская, профессор кафедры управления человеческими ресурсами, объясняет высокий уровень безработицы тем, что в регионах очень много молодежи, которые, к сожалению, с низким уровнем образования [9].

Молодым специалистам, всегда сложнее найти работу, так как нет опыта, или опыт есть, но его мало. Также профессор Варшавская утверждает, что экономика в СКФО, в большей мере, построена на предпринимательстве (частные магазины, малый бизнес). И в завершении хотелось бы добавить, что в СКФО уровень безработицы весьма высок, уровень жизни в регио- нах низок, большинство уезжают в другие города, но есть и те люди, которые получают пособия по безработице. Если сравнить выплаты пособий по безработице, например, с Москвой, пособие по безработице весьма маленькое. Но для большинства регионов СКФО это пособие является весьма значимым. Следует отметить, что такая ситуация происходит не только в СКФО. В России так же имеются и другие регионы с высоким уровнем безработицы. По данным Федеральной службы статистики в России 75 млн. работающих человек, из них 4,4 млн. человек являются безработными (см. рис. 7).

Исходя из вышесказанного, можно с уверенностью сделать вывод, что безработица в реги-

\begin{tabular}{|l|l|l|l|}
\hline Наименование & 2018 & 2019 & 2020 \\
\hline & & & \\
\hline Респ. Дагестан & 51,3 & 52 & 48,2 \\
\hline Респ. Ингушетия & 55,0 & 57,9 & 49,1 \\
\hline $\begin{array}{l}\text { Кабарднно-Балкар. } \\
\text { Респ. }\end{array}$ & 63,2 & 62,0 & 55,5 \\
\hline $\begin{array}{l}\text { Карачаево-Черкес. } \\
\text { Респ. }\end{array}$ & 50,5 & 47,9 & 45,4 \\
\hline $\begin{array}{l}\text { Респ. Северная Осе- } \\
\text { тия }\end{array}$ & 61,6 & 49,0 & 49,9 \\
\hline Чеченская Респ. & 56,9 & 56,4 & 52,2 \\
\hline $\begin{array}{l}\text { Ставропольский } \\
\text { край }\end{array}$ & 56,7 & 57,2 & 55,7 \\
\hline
\end{tabular}

Рисунок 6. Уровень занятости с 2018-2020 гг. 


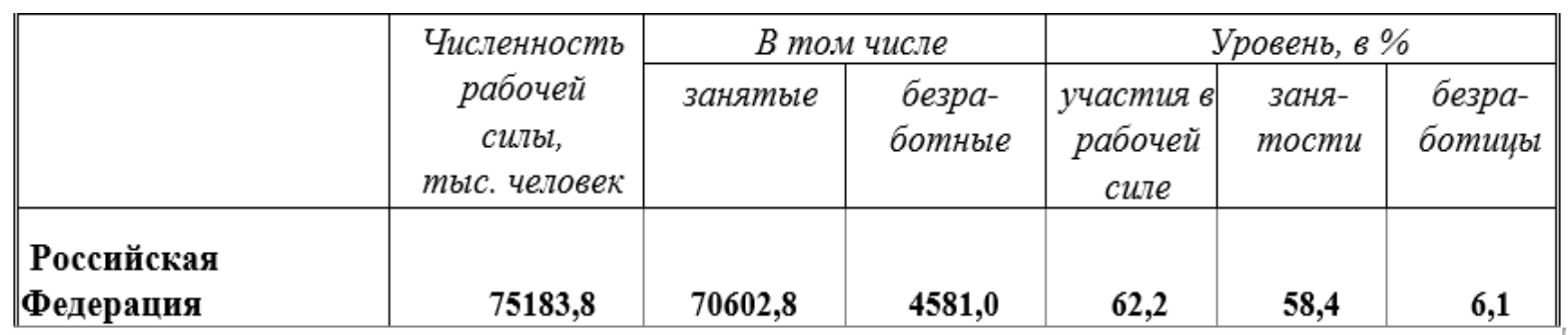

Рисунок 7. Данные Федеральной государственной службы статистики по России за 2020 год

онах СКФО растет. Занятость населения сильно упала в период за 2018-2020 год. Обусловлено это тем, что не соответствуют темпы создания рабочих мест и увеличения трудовых ресурсов. Для того, чтобы нормализовать данную ситуацию с безработицей, необходимо сделать акцент на сохранении рабочих мест. Во время пандемии многие профессии перешли на дистанционный режим работы, но, к сожалению, есть профессии, которые не могут перейти на дистанционный режим работы. Также необходимо дать стимул безработным людям, которые живут на пособия. Как показывает практика, пособие по безрабо- тице является существенным в регионах СКФО, и большинство граждан регионов просто не хотят выходить на работу и получать рабочий стаж.

Также необходимо уделить особое внимание гражданам с ограниченными возможностями. Создание рабочих мест для таких людей, благоприятно скажется на статистике. Реализация указанных мероприятий позволит улучшить ситуацию на региональном рынке труда. Но указанные меры невозможны без активного вмешательства государственной власти в решение данного вопроса.

\section{Библиографический список}

1. Маркс К. Капитал (1 том) // Маркс К., Энгельс Ф. Соч. 2-е изд. Т. 23. М.: Государственное издательство политической литературы, 1960.

2. Корнейчук, Б. В. Рынок труда: учебник для академического бакалавриата / Б. В. Корнейчук. - 2-е изд., испр. и доп.- Москва: Издательство Юрайт, 2019. - 263 с.

3. Федеральная служба государственной статистики Республика Дагестан [Электронный ресурс] - Режим доступа: https://dagstat.gks.ru/rintrud (дата обращения 09.03.2021)

4. Федеральная служба государственной статистики Республика Ингушетия [Электронный ресурс] - Режим доступа: https://stavstat.gks.ru/folder/29855 (дата обращения 09.03.2021)

5. Федеральная служба государственной статистики Кабардино-Балкарская Республика [Электронный ресурс] - Режим доступа: http://stavstat.old.gks.ru/wps/wcm/connect/rosstat_ts/stavstat/ru/statistics/kbrStat/ employment/ (дата обращения 09.03.2021)

6. Федеральная служба государственной статистики Карачаево-Черкесская Республика [Электронный ресурс] - Режим доступа: http://stavstat.old.gks.ru/wps/wcm/connect/rosstat_ts/stavstat/ru/statistics/kchrStat/ employment/ (дата обращения 09.03.2021)

7. Федеральная служба государственной статистики Чеченская Республика [Электронный ресурс] - Режим доступа: https://chechenstat.gks.ru/folder/38735 / (дата обращения 09.03.2021)

8. Федеральная служба государственной статистики Ставропольский край [Электронный ресурс] - Режим доступа https://stavstat.gks.ru/folder/28418 (дата обращения 09.03.2021)

9. Рамблер новости статья [Электронный ресурс] - Режим доступа https://news.rambler.ru/other/ 42538863-bezrabotitsu-v-ingushetii-obyasnili-urovnem-ekonomiki-xix-veka/ (дата обращения 09.03.2021) 